\title{
LOMBARDY AND VENETO BIOCULTURAL FINGERPRINT: A DRIVING FORCE FOR TOURISM AND RESIDENTIAL ATTRACTION
}

\author{
Luca Iseppi \\ Ting Fa Margherita Chang \\ Maurizio Droli \\ Department of Civil Engineering and Architecture, \\ University of Udine, Italy
}

\begin{abstract}
The approach to the territory's biocultural fingerprint can be very important when it comes to studying uniformities and differences among different regions. By examining the code of the attributes and the features, it is therefore possible to determine the landscapecultural uniformities which can create a common project for tourism and residential attraction. The differences underline emergencies of a cultural, natural, agricultural, and wine-gastronomic nature which are capable not only of rendering a territory identifiable but also of presenting it to integrated tourist packages and residential perspectives. The objective of this research is to verify the competitive ability which can enhance the potentialities of 'territorial capital'. This comparative study amongst the fingerprints of the Lombardy and Veneto regions uses a model which can appraise the tourism and residential attraction determining the attributes' code characterizing homogeneous sets of municipalities.

Keywords: regional model appraisal, biocultural fingerprint, competitiveness, landscapecultural characteristics, territorial capital potentialities, tourism attractiveness, innovation management.
\end{abstract}

\section{Introduction $^{24}$ \\ The biocultural fingerprint as a marker of the cultural heritage}

The landscape is considered the materialization of the flow of historical processes which generate the territorial organization intended as a tangible historical construct (Gambi, 2001). In this contest, landscape is an interaction between environment and society and configures itself as a material edification of space that could be see through the lens of the cultural heritage prisma referred to social structures, economic and demographic events and political institutions.

The historical reality necessitates a genetic and functional analysis which allow understanding how, when and which type of processes has formed the tangible realities where we live and work (Sereni, 1974). In 2007, Chang and Iseppi devised the concept of biocultural fingerprint as a tool to provide the genetic and functional identity map of the territory, characterizing its individuality. It is " $a$ projection on a space of synthetic attributes (crests) of a universe much more rich and varied, and therefore cannot be represented in all its complexity

\footnotetext{
${ }^{24}$ This section is common to the Authors
} 
because partly intangible" (Chang et al., 2007). The superstructure is represented by intangible human and natural capital and by services available in a specific area. This concept attempts to be more responsive to a balanced view of territory, avoiding to become reductionist. Such identity derives from both biocultural processes (biological, skill and knowledge) and population heritage prevailing in the territory. The processes involved are of dynamic nature and in continuous evolution; that specificity differentiates biocultural from individual fingerprint. The peculiarity of the intangible and dynamic biocultural fingerprint highlights the human, intangible and immaterial evolution of territorial capital. In fact landscape-cultural mosaic can assume consistent and sometimes invisible transformation in the long run.

The main objective of this paper is to put in evidence the biocultural crests as driving force for residential and tourist attraction through appropriate statistical methods that allows to verify the competitive ability which can enhance the potentialities of 'territorial capital' (Kunzmann, 2006). The aims are fourfold: a) to design a methodological architecture (model) able to create a complex and comprehensive database through mixed qualitative and quantitative elements derived from both censuses (Population, Agriculture, Industry and service) and guidebooks (tourist, naturalistic, wine-gastronomic); b) to find a method to quantify qualitative data and to weight qualitative and quantitative variables; c) to develop a synthetic residential and tourism attraction index allowing a comparison among different local entities; and d) to apply this complex portable methodological model to very important Italian economic regions, namely Lombardy and Veneto.

This comparative study amongst the fingerprints of the Lombardy and Veneto uses a model which can appraise the tourism and residential attraction and determining the attributes' code characterizing homogeneous sets of municipalities.

\section{The construction of the municipality database of Lombardy and Veneto $^{25}$}

To identify the sequence of Lombardy and Veneto regions biocultural fingerprint, it is therefore necessary to build two detailed databases at municipality level. This allows for a quantification of the territorial artmonumental, agricultural, natural and wine-gastronomic emergencies (crests). With respect to agricultural variables, the task is simple in that the data used is related to farm soil use which has been taken into consideration by the last General Agricultural Census (2010). This data, which is expressed in hectares, is related to 14 variables of soil use: Wheat, Other cereals (such as corn),

\footnotetext{
${ }^{25}$ This section is mainly due to Iseppi
} 
Horticultural and flower growth, Alternate fodder, Industrial plants, Grapevines, Olive trees, Fruits, Citrus trees, Arboreal hatcheries and ornamental plants, Timber, Lawns and pastures, Wood, Other surfaces. The corresponding Census labels are: WHEAT, O CER, HORT, FOD, INDCUL, GRAPEVINE, OLIVE TREES, FRUIT, CYTRUS, NURS_TREES, PAST, WOOD_ARB, WOODS, O_SURF. Two variables have been added from the wine-gastronomic database. They have been taken from the Industrial and Services Census, that is to say: Restaurant units (REST_U) and their Employees (REST_E). Finally, two other general and quantitative variables have been used: Population density (POP_DENS) and Educational (EDUC) level (number of high school graduates over 18 years of age). The total number of quantitative variables is 18 .

Eighteen qualitative variables have been collated in order to create the fingerprint, that is to say, the biocultural imprint of the Lombardy and Veneto regional territory.

The monumental and cultural variables are the following 7: the description of the emergencies (DESCR), the natural beauties which are different from those that are to be found in parks and in protected areas (PANOR), monuments or artistic-cultural emergencies (MONUM), recreational facilities (RICRE), prestigious urban contexts (CONTE) as well as the presence of maps (MAP) and sketches (DRAW).

The naturalistic database is built by qualitative variables which are taken from specific park protected and shrubby areas guidebooks: shrubby areas (SHRUB_A) and thin vegetation areas (THIN_A), sweet (SWEET_W) and brackish waters (BRACK_W), sport (SPORT), hobby (HOBBY), ethnographic museums, guided tours, etc. (VISIT), fauna (FAUNA), flora (FLORA), geological phenomena (GEOLO).

The wine-gastronomic variables have been summarized into 2 variables in order to avoid duplicating the agricultural database. They have been taken from the "Panorama" (PAN_CO) and "Slow Food" (SLO_CO) guidebooks.

The variables which have been taken into consideration total 37 of which 18 are quantitative and 19 are qualitative.

\section{Preliminary statistical elaborations and clustering ${ }^{26}$}

The following problem is how to go from qualitative data to a quantitative one when it comes to appraising artistic-monumental, natural, and wine-gastronomic emergencies. In order to overcome this obstacle what has been used is an important methodological piece of work (Piccinini, Taverna 2006) which allows for the quantification of the qualitative variables by appraising the attractiveness of sites.

\footnotetext{
${ }^{26}$ This section is mainly due to Iseppi
} 
The complete database (matrix $n$ rows $=$ number of towns; $m$ columns $=$ number of attributes), is composed by Lombardy (1536 towns x 37 attributes) and Veneto (581 towns $\times 37$ attributes) matrixes. This database has been subjected to the following elaborations: A) calculation of $\log _{10}\left(1+x_{i j}\right)$ where $x_{i j}$ represents every single cell of the matrix; B) normalization on the basis of the maximum value per column of each one of the 37 variables. The result is that each one varies from a range of $0-1 ; C$ ) cluster of the $n$ town cases in a given number. of clusters and representation of the clusters through geographical coordinates. The algorithm requires us to fix the best number of clusters in order to describe the characteristics of the towns. Using an interpolation method it has been established that 15 is the congruous number of required clusters for both regions so that significant information is not lost along the way (Iseppi, 2009); D) typological determination of clusters according to prevailing crests: monumental, natural, agricultural and gastronomic ones; E) description of the sequence of the characteristics of the most interesting typologies.

\section{The biocultural fingerprint of Lombardy and Veneto ${ }^{27}$}

Following a biological metaphor, the attribute represent an organism's genetic code. They provide important information which is related to different features of the characteristics that distinguish them. The organism is equivalent to the territory, which is the subject of the study and whose image, characteristics and features are revealed by the presence/absence of the attributes and by its combination. In some clusters this 'combination or genetic sequence' provides a unique territorial expression which highlights its identity.

For each cluster the crests have been emphasised and are indicated by number 1 which is meant for those indexes that are above the regional average of the cluster centers for each variable that has been studied. Number 0 has instead been allocated to those which are to be found below the average. From the analysis of the sequences of the attributes the following map has been performed (Table 1).

For space reasons, we omit the description of each binary sequence to concentrate to the two general variables, Population density and Education. The number of presences combination in the Veneto clusters (8 POP_DENS -8 EDUC) is superior to those of Lombardy (6 POP_DENS - 5 EDUC). There is a correlation between the degree of population density and the degree of education.

\footnotetext{
${ }^{27}$ This section is mainly due to Iseppi and Chang
} 
Proceeding of the International Scientifical Conference.

Volume II.

Fingerprint sequences and identity maps

Table1

\begin{tabular}{|c|c|c|c|c|c|c|c|c|c|c|c|c|c|c|c|c|c|c|c|c|c|c|c|c|c|c|c|c|c|c|c|}
\hline Lombardy & 1 & 2 & 3 & 4 & 5 & 6 & 7 & 8 & 9 & 10 & 11 & 12 & 13 & 14 & 15 & Veneto & 1 & 2 & 3 & 4 & 5 & 6 & 7 & 8 & 9 & 10 & 11 & 12 & 13 & 14 & 15 \\
\hline POP_DENS & 0 & 0 & 0 & 0 & 0 & 1 & 0 & 1 & 0 & 1 & 0 & 1 & 0 & 1 & 1 & POP_DENS & 1 & 1 & 1 & 0 & 1 & 0 & 0 & 1 & 0 & 0 & 0 & 1 & 0 & 1 & 1 \\
\hline DESCR & 0 & 0 & 0 & 0 & 0 & 0 & 0 & 0 & 1 & 1 & 0 & 0 & 0 & 1 & 1 & DESCR & 0 & 0 & 0 & 1 & 1 & 0 & 0 & 1 & 0 & 0 & 0 & 1 & 0 & 0 & 0 \\
\hline MAP & 0 & 0 & 0 & 0 & 0 & 0 & 0 & 0 & 0 & 1 & 0 & 0 & 0 & 1 & 1 & MAP & 0 & 0 & 0 & 1 & 1 & 0 & 0 & 1 & 0 & 0 & 0 & 0 & 0 & 0 & 0 \\
\hline DRAW & 0 & 0 & 0 & 0 & 0 & 0 & 0 & 0 & 0 & 1 & 0 & 0 & 0 & 1 & 1 & DRAW & 0 & 0 & 0 & 0 & 1 & 0 & 0 & 1 & 0 & 0 & 0 & 0 & 0 & 0 & 0 \\
\hline PANOR & 1 & 0 & 0 & 0 & 1 & 0 & 0 & 0 & 1 & 1 & 0 & 1 & 0 & 1 & 1 & PANOR & 0 & 0 & 0 & 1 & 0 & 0 & 0 & 1 & 1 & 0 & 0 & 1 & 0 & 0 & 0 \\
\hline MONUM & 0 & 0 & 0 & 0 & 0 & 0 & 0 & 0 & 0 & 1 & 0 & 0 & 0 & 1 & 1 & MONUM & 0 & 0 & 0 & 1 & 1 & 0 & 0 & 1 & 0 & 1 & 0 & 0 & 0 & 0 & 0 \\
\hline RICRE & 0 & 0 & 0 & 0 & 0 & 0 & 0 & 0 & 0 & 1 & 0 & 0 & 0 & 1 & 1 & RICRE & 0 & 0 & 0 & 1 & 1 & 0 & 0 & 1 & 0 & 0 & 0 & 0 & 0 & 0 & 0 \\
\hline CONTE & 0 & 0 & 0 & 0 & 0 & 0 & 0 & 0 & 0 & 1 & 0 & 0 & 0 & 1 & 1 & CONTE & 0 & 0 & 0 & 1 & 1 & 0 & 0 & 1 & 0 & 1 & 0 & 0 & 0 & 0 & 0 \\
\hline EDUC & 0 & 0 & 0 & 0 & 0 & 0 & 0 & 1 & 0 & 1 & 0 & 1 & 0 & 1 & 1 & EDUC & 1 & 0 & 0 & 0 & 1 & 0 & 0 & 1 & 0 & 1 & 0 & 1 & 0 & 0 & 1 \\
\hline SHRUB_A & 0 & 0 & 0 & 0 & 0 & 0 & 0 & 1 & 1 & 0 & 0 & 0 & 0 & 0 & 0 & SHRUB_A & 1 & 0 & 0 & 0 & 0 & 0 & 0 & 0 & 0 & 1 & 0 & 0 & 1 & 0 & 0 \\
\hline THIN_A & 0 & 0 & 0 & 0 & 1 & 0 & 0 & 0 & 1 & 0 & 0 & 0 & 0 & 0 & 0 & THIN_A & 0 & 0 & 0 & 1 & 0 & 0 & 0 & 0 & 0 & 1 & 1 & 0 & 1 & 0 & 0 \\
\hline SWEET_W & 1 & 0 & 0 & 0 & 1 & 0 & 0 & 0 & 0 & 1 & 0 & 1 & 0 & 0 & 1 & SWEET_W & 0 & 0 & 0 & 0 & 0 & 0 & 0 & 0 & 0 & 0 & 0 & 1 & 0 & 0 & 0 \\
\hline BRACK_W & 0 & 0 & 0 & 0 & 0 & 0 & 0 & 0 & 0 & 0 & 0 & 0 & 0 & 0 & 0 & BRACK_W & 0 & 0 & 0 & 0 & 0 & 0 & 1 & 0 & 0 & 0 & 0 & 0 & 0 & 0 & 0 \\
\hline FAUNA & 1 & 0 & 0 & 0 & 1 & 0 & 0 & 0 & 1 & 1 & 0 & 0 & 0 & 0 & 0 & FAUNA & 1 & 0 & 0 & 1 & 0 & 0 & 1 & 0 & 0 & 1 & 0 & 0 & 1 & 0 & 0 \\
\hline FLORA & 1 & 0 & 0 & 0 & 1 & 0 & 0 & 0 & 1 & 0 & 0 & 0 & 0 & 0 & 0 & FLORA & 1 & 0 & 0 & 1 & 0 & 0 & 1 & 0 & 0 & 1 & 1 & 1 & 1 & 0 & 0 \\
\hline GEOLO & 1 & 0 & 0 & 0 & 1 & 0 & 0 & 0 & 1 & 0 & 0 & 1 & 0 & 0 & 0 & GEOLO & 1 & 0 & 0 & 1 & 0 & 0 & 1 & 0 & 0 & 1 & 1 & 1 & 1 & 0 & 0 \\
\hline SPORT & 1 & 0 & 0 & 0 & 1 & 0 & 0 & 0 & 1 & 0 & 0 & 0 & 0 & 0 & 0 & SPORT & 0 & 0 & 0 & 0 & 0 & 0 & 0 & 0 & 0 & 0 & 1 & 0 & 0 & 0 & 0 \\
\hline HOBBY & 1 & 0 & 0 & 0 & 0 & 0 & 0 & 0 & 0 & 1 & 0 & 1 & 0 & 0 & 0 & HOBBY & 1 & 0 & 0 & 1 & 0 & 0 & 1 & 0 & 0 & 1 & 1 & 1 & 1 & 0 & 0 \\
\hline VISIT & 1 & 0 & 0 & 0 & 1 & 0 & 0 & 0 & 1 & 1 & 0 & 1 & 0 & 0 & 1 & VISIT & 1 & 0 & 0 & 1 & 0 & 0 & 1 & 0 & 0 & 1 & 1 & 1 & 0 & 0 & 0 \\
\hline WHEAT & 1 & 1 & 0 & 1 & 0 & 0 & 0 & 1 & 0 & 1 & 0 & 0 & 0 & 1 & 1 & WHEAT & 1 & 0 & 1 & 0 & 1 & 0 & 1 & 1 & 0 & 0 & 0 & 1 & 0 & 1 & 1 \\
\hline O_CER & 1 & 1 & 0 & 1 & 0 & 1 & 0 & 1 & 0 & 1 & 0 & 0 & 1 & 1 & 1 & O_CER & 1 & 0 & 1 & 0 & 1 & 0 & 1 & 1 & 0 & 1 & 0 & 1 & 0 & 1 & 1 \\
\hline HORT & 1 & 1 & 0 & 1 & 0 & 0 & 0 & 0 & 0 & 1 & 0 & 0 & 0 & 1 & 1 & HORT & 1 & 0 & 1 & 0 & 1 & 0 & 1 & 1 & 0 & 0 & 0 & 1 & 0 & 1 & 0 \\
\hline FOD & 1 & 1 & 0 & 1 & 0 & 1 & 0 & 1 & 0 & 1 & 0 & 0 & 0 & 1 & 1 & FOD & 1 & 0 & 1 & 0 & 1 & 0 & 1 & 1 & 0 & 1 & 0 & 1 & 0 & 1 & 1 \\
\hline INDCUL & 1 & 1 & 0 & 1 & 0 & 0 & 0 & 0 & 0 & 1 & 0 & 0 & 1 & 1 & 1 & INDCUL & 1 & 0 & 1 & 0 & 1 & 0 & 1 & 1 & 0 & 0 & 0 & 1 & 0 & 1 & 1 \\
\hline GRAPE & 1 & 1 & 1 & 0 & 0 & 0 & 0 & 0 & 0 & 0 & 0 & 0 & 0 & 1 & 1 & GRAPEWINE & 1 & 1 & 0 & 0 & 1 & 0 & 0 & 1 & 0 & 0 & 0 & 1 & 0 & 1 & 1 \\
\hline OLIVE TREES & 0 & 0 & 1 & 0 & 0 & 0 & 0 & 0 & 0 & 0 & 0 & 1 & 0 & 1 & 1 & OLIVE TREES & 1 & 1 & 0 & 0 & 1 & 0 & 0 & 1 & 0 & 0 & 0 & 0 & 0 & 0 & 1 \\
\hline CYTRUS & 1 & 1 & 1 & 0 & 0 & 0 & 0 & 0 & 0 & 1 & 0 & 0 & 0 & 0 & 1 & CYTRUS & 1 & 1 & 1 & 0 & 0 & 0 & 0 & 0 & 0 & 0 & 1 & 0 & 0 & 1 & 1 \\
\hline FRUIT & 1 & 1 & 1 & 0 & 0 & 0 & 0 & 0 & 0 & 1 & 0 & 1 & 0 & 1 & 0 & FRUIT & 0 & 0 & 1 & 0 & 1 & 0 & 1 & 1 & 0 & 1 & 1 & 0 & 0 & 1 & 1 \\
\hline NURS_TREES & 1 & 1 & 0 & 0 & 0 & 0 & 0 & 1 & 0 & 1 & 0 & 0 & 0 & 1 & 1 & NURS_TREES & 1 & 0 & 0 & 0 & 1 & 0 & 0 & 1 & 0 & 0 & 0 & 1 & 0 & 1 & 1 \\
\hline PAST & 1 & 0 & 0 & 0 & 1 & 0 & 0 & 0 & 1 & 1 & 1 & 0 & 0 & 1 & 1 & PAST & 0 & 0 & 0 & 1 & 1 & 0 & 0 & 1 & 1 & 1 & 1 & 0 & 1 & 0 & 1 \\
\hline WOOD_ARB & 1 & 1 & 0 & 1 & 0 & 0 & 0 & 0 & 0 & 1 & 0 & 0 & 1 & 1 & 1 & WOOD_ARB & 0 & 0 & 1 & 0 & 1 & 0 & 1 & 1 & 0 & 1 & 0 & 1 & 0 & 1 & 0 \\
\hline WOODS & 0 & 0 & 1 & 0 & 1 & 0 & 0 & 0 & 1 & 0 & 1 & 1 & 0 & 1 & 1 & WOODS & 1 & 0 & 0 & 1 & 1 & 0 & 0 & 0 & 1 & 1 & 1 & 0 & 0 & 0 & 0 \\
\hline O_SURF & 1 & 1 & 0 & 1 & 0 & 0 & 0 & 0 & 0 & 1 & 0 & 0 & 0 & 1 & 1 & O_SURF & 1 & 0 & 0 & 1 & 1 & 0 & 1 & 1 & 0 & 0 & 0 & 1 & 0 & 1 & 1 \\
\hline REST_U & 0 & 0 & 0 & 0 & 0 & 0 & 0 & 0 & 0 & 1 & 0 & 0 & 0 & 1 & 1 & REST_U & 1 & 0 & 0 & 1 & 1 & 0 & 1 & 1 & 0 & 0 & 0 & 1 & 0 & 1 & 1 \\
\hline REST_E & 0 & 0 & 0 & 0 & 0 & 0 & 0 & 1 & 0 & 1 & 0 & 0 & 0 & 1 & 1 & REST_E & 0 & 0 & 0 & 1 & 1 & 0 & 0 & 1 & 0 & 1 & 0 & 1 & 0 & 0 & 1 \\
\hline PAN_CO & 0 & 0 & 0 & 0 & 0 & 0 & 0 & 0 & 0 & 1 & 0 & 0 & 0 & 1 & 1 & PAN_CO & 0 & 0 & 0 & 1 & 1 & 0 & 0 & 1 & 0 & 0 & 0 & 0 & 0 & 0 & 0 \\
\hline SLO_CO & 0 & 0 & 0 & 0 & 0 & 0 & 0 & 0 & 0 & 0 & 0 & 0 & 0 & 1 & 1 & SLO_CO & 0 & 0 & 0 & 0 & 1 & 0 & 0 & 1 & 0 & 0 & 0 & 0 & 0 & 0 & 0 \\
\hline
\end{tabular}




\section{Lombardy and Veneto biocultural fingerprints: codes and attraction indexes ${ }^{28}$}

The structure and composition of the tourism and residential supply varies and is based on territorial reference. It is therefore possible to determine the sequence of the attributes which characterises the biocultural fingerprint. What occurs is that every municipality cluster is capable of offering an integrated set of attributes (material and immaterial) which is inseparable from such a supply. For each of the two regions a type of attraction index has been calculated which expresses the degree of the presence of each characteristics which have been articulated in the different features. Every cluster is characterized by a given combination of characteristic features which is called code (Monumental-M, Naturalistic-N, Agricultural-A, Wine-Gastronomy-E). The weight of each characteristic is given by the sum of the features emphasised by the value number 1 when present and 0 when absent (Table 1). This therefore means that the range value which is given to every characteristic will be between 0 (absence of feature) and 1 (presence of all features). The attraction index is the sum of the ratios of each group of characteristics on its total maximum. The comparison of cluster attraction indexes allows to verify the competitive ability which can enhance the potentialities of 'territorial capital' and becoming the driving force for tourism and residential attraction.

The presence of the Density feature, which is highlighted with value 1 , has been identified with the letter U (urban) whereas its absence (value 0) has been identified with the letter $\mathrm{R}$ (rural). With regards to the Education feature the presence has been identified with the letter E. Attraction indexes of the 15 regional clusters have been listed in following Table 2 allowing the comparison of identity codes that characterize Lombardy and the Veneto biocultural fingerprint. The table emphasises which clusters of the Veneto region have a more or less similar combination of attributes respect Lombardy's clusters and vice-versa.

\section{Main findings ${ }^{29}$}

The Veneto region has a more diversified landscape-cultural mosaic compared to Lombardy. The fact is suggested by the variety of attribute codes which are above the average. While in Lombardy there is a polarization of its clusters, with an index of attractiveness greater than one, on only 3 attribute codes (6 in Lombardy and 8 in Veneto), in Veneto the clusters are distribute among 7 attribute codes. Actually, in Lombardy there are only the codes CAW_U_E,

\footnotetext{
${ }^{28}$ This section is mainly due to Iseppi

${ }^{29}$ This section is common to Iseppi and Chang
} 
(Culture, Agriculture and Wine-gastronomy in Urban contexts with high education levels), NA (Nature and Agriculture in Rural area with low

Table 2

\section{Tourism attraction and residential indexes and codes: Lombardy and Veneto}

\begin{tabular}{|c|c|c|c|c|c|c|c|}
\hline \multicolumn{8}{|c|}{ Lombardy } \\
\hline $\begin{array}{c}\text { Cluster } \\
\text { No. }\end{array}$ & $\begin{array}{l}\text { No. } \\
\text { Muni- } \\
\text { cipali- } \\
\text { ties }\end{array}$ & $\begin{array}{c}\text { Cluster } \\
\text { municipali- } \\
\text { ties }\end{array}$ & $\begin{array}{l}\text { Attraction } \\
\text { Index }\end{array}$ & $\begin{array}{c}\text { Population } \\
\text { density }\end{array}$ & $\begin{array}{c}\text { Education } \\
\text { degree }\end{array}$ & $\begin{array}{l}\text { Characteristic } \\
\text { features }\end{array}$ & Code \\
\hline 15 & 1 & Milano & 3.13 & 1 & 1 & $\begin{array}{l}1 \mathrm{C} ; 2 / 10 \mathrm{~N} ; \\
13 / 14 \mathrm{~A} ; 1 \mathrm{~W}\end{array}$ & $\begin{array}{l}\text { CAW_- } \\
\text { U_E }\end{array}$ \\
\hline 10 & 7 & $\begin{array}{l}\text { Mantova. } \\
\text { Pavia etc. }\end{array}$ & 2.94 & 1 & 1 & $\begin{array}{l}1 \mathrm{C} ; 4 / 10 \mathrm{~N} ; \\
11 / 14 \mathrm{~A} ; 3 / 4 \mathrm{~W}\end{array}$ & $\begin{array}{l}\text { CAW_- } \\
\text { U_E }\end{array}$ \\
\hline 14 & 4 & $\begin{array}{l}\text { Bergamo } \\
\text { Brescia etc. }\end{array}$ & 2.93 & 1 & 1 & $\begin{array}{l}1 \mathrm{C} ; 0 \mathrm{~N} ; 13 / 14 \\
\mathrm{~A} ; 1 \mathrm{~W}\end{array}$ & $\begin{array}{l}\text { CAW_- } \\
\text { U_E }\end{array}$ \\
\hline 1 & 14 & $\begin{array}{l}\text { Abbiategras } \\
\text { so.Curtatone } \\
\text { etc. }\end{array}$ & 1.70 & 0 & 0 & $\begin{array}{l}1 / 7 \mathrm{C} ; 7 / 10 \mathrm{~N} \\
12 / 14 \mathrm{~A} ; 0 \mathrm{~W}\end{array}$ & NA \\
\hline 9 & 10 & \begin{tabular}{|l|} 
Bormio \\
Livigno ect. \\
\end{tabular} & 1.13 & 0 & 0 & $\begin{array}{l}2 / 7 \mathrm{C} ; 7 / 10 \mathrm{~N} ; \\
2 / 14 \mathrm{~A} ; 0 \mathrm{~W}\end{array}$ & $\mathbf{N}$ \\
\hline 5 & 38 & \begin{tabular}{|l|} 
Varese, \\
Bellagio etc. \\
\end{tabular} & 0.99 & 0 & 0 & $\begin{array}{l}\text { 1/7 C; } 7 / 10 \mathrm{~N} ; \\
2 / 14 \mathrm{~A} ; 0 \mathrm{~W} \\
\end{array}$ & $\mathbf{N}$ \\
\hline Other 9 & $\begin{array}{c}\text { Other } \\
\ldots\end{array}$ & & 3.52 & & & & \\
\hline Total & & $\ldots$ & 16.34 & & & & \\
\hline \multicolumn{8}{|c|}{ Veneto } \\
\hline $\begin{array}{c}\text { Cluster } \\
\text { No. }\end{array}$ & $\begin{array}{l}\text { No. } \\
\text { Munic- } \\
\text { ipalities }\end{array}$ & \begin{tabular}{|c|} 
Cluster \\
municipali- \\
ties
\end{tabular} & $\begin{array}{l}\text { Attraction } \\
\text { Index }\end{array}$ & $\begin{array}{l}\text { Population } \\
\text { density }\end{array}$ & $\begin{array}{c}\text { Education } \\
\text { degree }\end{array}$ & $\begin{array}{l}\text { Characteristic } \\
\text { features }\end{array}$ & Code \\
\hline 8 & 2 & $\begin{array}{l}\text { Venezia. } \\
\text { Padova }\end{array}$ & 2.86 & 1 & 1 & $\begin{array}{l}1 \mathrm{C} ; 0 \mathrm{~N} ; 12 / 14 \\
\mathrm{~A} ; 1 \mathrm{~W}\end{array}$ & $\begin{array}{l}\text { CAW_- } \\
\text { U_E }\end{array}$ \\
\hline 5 & 2 & \begin{tabular}{|l|} 
Verona. \\
Vicenza \\
\end{tabular} & 2.79 & 1 & 1 & \begin{tabular}{|l|}
$6 / 7 \mathrm{C} ; 0 \mathrm{~N} ;$ \\
$13 / 14 \mathrm{~A} ; 1 \mathrm{~W}$ \\
\end{tabular} & $\begin{array}{l}\overline{C A W} \text { _ } \\
\text { U_E E }\end{array}$ \\
\hline 4 & 1 & Cortina & 2.42 & 0 & 0 & $\begin{array}{l}6 / 7 \mathrm{C} ; 6 / 10 \mathrm{~N} \\
3 / 14 \mathrm{~A} ; 3 / 4 \mathrm{~W}\end{array}$ & CNW \\
\hline 12 & 11 & Treviso etc. & 1.93 & 1 & 1 & $\begin{array}{l}2 / 7 \mathrm{C} ; 5 / 10 \mathrm{~N} ; \\
9 / 14 \mathrm{~A} ; 2 / 4 \mathrm{~W} \\
\end{array}$ & $\begin{array}{l}\text { NAW_- } \\
\text { U_E }\end{array}$ \\
\hline 10 & 4 & Belluno etc. & 1.66 & 0 & 1 & $\begin{array}{l}2 / 7 \mathrm{C} ; 7 / 10 \mathrm{~N} \\
6 / 14 \mathrm{~A} ; 1 / 4 \mathrm{~W}\end{array}$ & $\mathbf{N} \_\mathbf{E}$ \\
\hline 1 & 15 & $\begin{array}{l}\text { Abano } \\
\text { Montegrotto } \\
\text { etc. }\end{array}$ & 1.64 & 1 & 1 & $\begin{array}{l}0 \mathrm{C} ; 6 / 10 \mathrm{~N} ; \\
11 / 14 \mathrm{~A} ; 1 / 4 \mathrm{~W}\end{array}$ & $\begin{array}{l}\text { NA_U_U } \\
\text { E }\end{array}$ \\
\hline 7 & 9 & \begin{tabular}{|l|} 
Adria, Porto \\
Tolle etc.
\end{tabular} & 1.42 & 0 & 0 & \begin{tabular}{|l|}
$0 \mathrm{C} ; 6 / 10 \mathrm{~N} ;$ \\
$8 / 14 \mathrm{~A} ; 1 / 4 \mathrm{~W}$ \\
\end{tabular} & NA \\
\hline 15 & 52 & $\begin{array}{l}\text { Bassano } \\
\text { Conegliano } \\
\text { etc. } \\
\end{array}$ & 1.29 & 1 & 1 & $\begin{array}{l}0 \mathrm{C} ; 0 \mathrm{~N} ; 11 / 14 \\
\mathrm{~A} ; 2 / 4 \mathrm{~W}\end{array}$ & $\underset{-\mathbf{E}}{\mathbf{A W} \mathbf{U}}$ \\
\hline Other 7 & Other & $\ldots$ & 2.63 & & & & \\
\hline Total & & & 18.64 & & & & \\
\hline
\end{tabular}


Education levels) and $\mathrm{N}$ (Nature only) of which only $\mathrm{N}$ is an exclusive code for Lombardy. In Veneto, in addition to these, there emerge other 5 unique attribute codes highly attractive: CNW (Culture, Nature and Food \& Wine in borderline Rural/Urban areas with low Education level), NAW_U_E (Nature, Agriculture, Food \& Wine in Urban area with Educated population); N_E (Nature in mixed rural/urban areas with high Education level), NA_U_E (Nature, Agriculture in Urban areas highly Educated), AW_U_E (Agriculture, Food \& Wine in Urban and Educational contexts).

Consequently, the attraction index of Veneto is higher than that of Lombardy (18.64 and 16.34 respectively) reflecting a greater potential driving force of Veneto respect to Lombardy. It should be noted that in the last 10 years Veneto attractiveness index has decreased by two points (Chang et al., 2010) because of increased specialization in agriculture which has impoverished its rural landscape. Nevertheless, the major residential and tourism attraction must be ascribed to Milan (Lombardy) which, standing alone, forms the cluster No. 15 (Table 2). It is followed by other two clusters (No. 10 and No. 14) always in Lombardy. The first consists of Como, Monza, Lodi, Mantua, Crema, Vigevano and Pavia towns. The second consists of Bergamo, Brescia, Cremona and Desenzano del Garda. They are medium-sized cities with an important cultural, agricultural and wine-gastronomic heritage.

Clusters sharing the CAW_U_E code in Lombardy and in Veneto are those with the greatest cluster attraction index, cluster 8 Venice and Padua and cluster 5 Verona and Vicenza. They have nearly the same characteristics that create attractiveness in Lombardy.

The number of Lombardy clusters more dissimilar to those of the Veneto and vice versa are 3 and 2 respectively, marked with the CAW_U_E code (first column Table 2, clusters 15, 10 and 14 in Lombardy and clusters 5 and 8 in Veneto). These clusters include upper most 12 large and medium-sized cities in Lombardy and 4 in Veneto. But the degree of similarity among them is on the contrary high. In both regions, the attraction indexes for tourism and residences of these 16 cities and towns are the highest due to distinct architectural, cultural, agricultural and wine-gastronomic emerging features. The population density and the education degree are significantly above the average.

The clusters of Veneto more similar to those of Lombardy and vice versa are characterized by the pre-eminence of rurality (code _R) with no other attributes (clusters 6 and 9 in Veneto and clusters 13, 7, 11, 3 in Lombardy). The number of municipalities involved is very high (97 in Veneto and 817 in Lombardy). The attraction indexes are the lowest. In these territories special characteristics of touristic or residential value are absent. The population density and the education degree are not significant and below the average. The study findings demonstrated that even in the richest regions of the post-modern Italy the educational level and degree of rurality are still inversely related. However high 
population density by itself (code _U) does not imply high education levels. The involved clusters are 2 with a total of 318 municipalities (219 in Lombardy and 99 in Veneto). Worthy remarking that, in the administrative division, the Lombardy main cities outskirts very often appear as autonomous municipalities and most of it belong to these clusters. Furthermore in Veneto some small towns reveal to be densely populated especially in the mountain areas due to their limited territory.

Nevertheless, this correlation is not a perfect coincidence. In Veneto clusters 10 (Belluno, Feltre, etc.) and 13 (Longarone, Ponte nelle Alpi, etc.) show a low population density and a high-level of education whereas for cluster 2 (Piovene Rocchette, Thiene, etc.) the opposite occurs, due mainly to urban and rural sprawl. For the Lombardy the last exception regards only cluster 6 (Brebbia, Assago, etc.) with a high population density and a relatively low educational level.

\section{Conclusions $^{30}$}

The main results are as follows: i) Veneto region owns more differentiated and rich landscape-cultural mosaic than Lombardy, owing to naturalistic emerging features particularly the recognized world heritage Dolomites; ii) Milan in Lombardy possesses the most tourism and residential attraction code, a collection of excellent monumental, artistic, cultural, agricultural and winegastronomic characteristics in an urban context with a very high education level, that forms its peculiar identity. The same code but with a little lower tourism and residential attraction indexes distinguishes the identities of other 15 medium-sized cities, 11 in Lombardy (e.g. Pavia, Mantua, Bergamo, Brescia, ...) and 4 in Veneto (Venice, Padua, Verona and Vicenza); iii) the second most attractive code is owned by the fashionable mountain site of Cortina, a set of cultural, naturalistic and wine-gastronomic excellences where house prices are among the highest in Italy; iv) the third tourism and residential attraction code is owned by the so called 'Marca Trevigiana', a particular area, centred on Treviso, well known to be one of the richest of Italy, a whole of high quality naturalistic, agricultural, wine-gastronomic crests in an urbanized environment with high educational level; v) other codes revealed to have significant attraction indexes, two lie in Lombardy while four in Veneto, due to the lower degree of diversification of Lombardy with respect to Veneto. All these last codes except one (agriculture alone) give pre-eminence to naturalistic features, in few cases coupled with agricultural or wine-gastronomic features; vi) lowest tourism and residential attraction indexes have been found for the vast majority of the municipalities in the two regions. The features of those clusters are mainly urban or rural without any significant attribute of touristic or residential value. Among

\footnotetext{
${ }^{30}$ This section is mainly due to Droli
} 
these, the most valuable areas possess the naturalistic features. Furthermore, it has been evidenced that the population density and the educational level are not significant and below the average in those municipalities. The study findings demonstrated that even in the richest regions of the post-modern Italy the educational level and degree of ruralisation are still inversely related. From these results, it appears that the presence/absence of parks and protected areas (nature features) may create a super additive driving force to strengthening tourism and residential value chains. From the innovation management point of view, in the field of touristic and residential perspectives, the biocultural fingerprint can help amplifying the competitive advantage and the setbacks on which to base territorial policy (club of services, strategic alliances among firms, ecological sustainability, etc.).

\section{Summary $^{31}$}

The concept of biocultural fingerprint as a tool to provide the genetic and functional identity map of the territory characterizing its individuality as been devised by Chang and Iseppi in 2007. The biocultural fingerprint is '... a projection on a space of synthetic attributes (crests) of a universe much more rich and varied, and therefore hardly to represent in all its complexity due to diverse intangible characteristics and the features'. The fingerprint superstructure is represented by intangible human and natural capital coupled with services available in a specific area. The aim of this paper is fourfold: a) to design a methodological architecture (model) able to create a complex and comprehensive database through mixed qualitative and quantitative elements derived from both censuses (Population, Agriculture, Industry and service) and guidebooks (tourist, naturalistic, wine-gastronomic); b) to find a method to quantify qualitative data and to weight qualitative and quantitative variables; c) to develop a synthetic residential and tourism attraction index allowing a comparison among different local entities; and d) to apply this complex portable methodological model to very important Italian economic regions, namely Lombardy and Veneto.

The main results are as follows: i) Veneto region owns more differentiated and rich landscape-cultural mosaic than Lombardy, owing to naturalistic emerging features particularly the recognized world heritage Dolomites; ii) Milan in Lombardy possesses the most tourism and residential attraction code, a collection of excellent monumental, artistic, cultural, agricultural and wine-gastronomic characteristics in an urban context with a very high education level, that forms its peculiar identity. The same code but with a little lower tourism and residential attraction indexes distinguishes the identities of other 15 medium-sized cities, 11 in Lombardy (e.g. Pavia, Mantua, Bergamo, Brescia, ...) and 4 in Veneto (Venice, Padua, Verona and Vicenza); iii) the second most attractive code is owned by the fashionable mountain site of Cortina, a set of cultural, naturalistic and wine-gastronomic excellences where house prices are among the highest in Italy; iv) the third tourism and residential attraction code is owned by the

\footnotetext{
${ }^{31}$ This section is common to the Authors
} 
so called 'Marca Trevigiana', a particular area, centred on Treviso, well known to be one of the richest of Italy, a whole of high quality naturalistic, agricultural, winegastronomic crests in an urbanized environment with high educational level; v) other codes revealed to have significant attraction indexes, two lie in Lombardy while four in Veneto, due to the lower degree of diversification of Lombardy with respect to Veneto (Chang, Iseppi, 2011; 2012). All these last codes except one (agriculture alone) give pre-eminence to naturalistic features, in few cases coupled with agricultural or wine-gastronomic features; vi) lowest tourism and residential attraction indexes have been found for the vast majority of the municipalities in the two regions. The features of those clusters are mainly urban or rural without any significant attribute of touristic or residential value. Among these, the most valuable areas possess the naturalistic features. Furthermore, it has been evidenced that the population density and the educational level are not significant and below the average in those municipalities. The study findings demonstrated that even in the richest regions of the post-modern Italy the educational level and degree of rurality are still inversely related. From these results, it appears that the presence/absence of parks and protected areas (nature features) may create a super additive driving force to strengthen tourism and residential value chains.

Acknowledgement: the Authors greatly appreciated Mohamed Yassin valuable comments and suggestions.

\section{Bibliography}

1. Chang, T.F.M.; \& Iseppi, L.; \& Piccinini, L.C. (2007). Paesaggi: una fingerprint bioculturale. Atti del Convegno Internazionale Vestire il Paesaggio, 44-46, Pistoia.

2. Chang, T.F.M.; \& Iseppi, L.; \& Piccinini, L.C. (2010). Attrattività turistica e fingerprint bioculturale del territorio. Un confronto tra Veneto e Friuli Venezia Giulia. Economia e Diritto Agroalimentare, 2, 245-268.

3. Chang, T. F. M.; \& Iseppi, L. (2011). Specialization versus Diversification in EU Economies: a Challenge for Agro-food? Transition Studies Review, 18, 1, 16-37.

4. Chang, T. F. M.; \& Iseppi, L. (2012). EU Agro-Food Chain and Vertical Integration Potentiality: a Strategy for Diversification? Transition Studies Review, 19, 1, 107-130.

5. Gambi, L. (2001). Paesaggio. Enciclopedia Italiana Treccani Appendice, 395-396.

6. Iseppi, L. (2009). L'uso del suolo aziendale agricolo nei comuni italiani. Metodo per l'analisi del mosaico paesistico-ambientale e applicazione all'Italia. Udine: Forum Editrice.

7. Kunzmann, K. R. (2006). Spatial Development and Territorial Cohesion in Europe. In Altrock, U.; \& Güntner, S.; \& Huning, S.; \& Peters, D. Spatial Planning and Urban Development in the New EU Members States. England: Ed. Ashgate.

8. Sereni, E. (1974). Storia del paeasaggio agrario italiano. Bari: Laterza.

9. Taverna, M; \& Piccinini, L. C. (2006). Dallo spazio edonico locale al turismo globale. Agribusiness paesaggio \& ambiente, 3, 9, $218-228$. 


\begin{tabular}{|r|l|}
\hline Luca Iseppi & Department of Civil Engineering and \\
& Architecture, \\
& University of Udine, Italy \\
& E-mail: luca.iseppi@, uniud.it \\
\hline Ting Fa Margherita & Department of Civil Engineering and \\
Chang & Architectur. \\
& University of Udine, Italy \\
& E-mail: chang@,uniud.it \\
\hline Maurizio Droli & Department of Civil Engineering and \\
& Architecture, \\
& University of Udine, Italy \\
& E-mail: maurizio.droli@,uniud.it \\
\hline
\end{tabular}

